\title{
Phenol Removal and Bioaugmentation Potential Analysis of Different Bacterial Strains in Wastewater
}

\author{
Szabolcs Szilveszter ${ }^{1}$, Dezső-Róbert Fikó ${ }^{1,2}$, István Máthé ${ }^{1}$, Tamás Felföldi ${ }^{1,3}$ \\ ${ }^{1}$ Sapientia Hungarian University of Transylvania, Department of Bioengineering \\ Libertăţii Sq. nr. 1, MiercureaCiuc, Romania \\ szilveszterszabolcs@sapientia.siculorum.ro; matheistvan@sapientia.siculorum.ro \\ ${ }^{2}$ University Politehnica of Bucharest, Faculty of Applied Chemistry and Material Sciences \\ RO-011061 Polizu 1-7 Bucharest, Romania \\ fiko_robi@yahoo.com \\ ${ }^{3}$ Eötvös Loránd University, Department of Microbiology \\ Pázmány Péter sétány 1/C, Budapest, Hungary \\ tamas.felfoldi@gmail.com
}

\section{Extended Abstract}

Wastewater from various industrial processes such as oil refineries, resins and coke manufacturing plants, steel and pharmaceutical industries contain phenols and phenolic compounds [1]. Phenolic compounds are toxic to aquatic life, plants and many other organisms, as a consequence it is necessary to reduce the phenol content in the wastewater prior to discharge to a maximum level of $1 \mathrm{mgL}^{-1}$ limited by the World Health Organization (WHO) [2, 3]. Technologies for the treatment of phenol include chemical oxidation, adsorption, membrane separation and biological treatment. Biological treatment has been shown to be the most cost-effective, practical and versatile approach as it leads to the complete mineralization of phenol [1]. The objective of our study was to investigate phenol degradation efficiency and bioaugmentation potential of three bacterial strains isolated from a landfill leachate-treating bioreactor.

Samples were taken from a sequencing batch reactor treating landfill leachate, with the aim to isolate bacteria with phenol degradation potential, and to test further phenol degradation in synthetic wastewater under laboratory conditions [4]. Three bacterial strains named Acinetobacter townerii CFII-87, Acinetobacter johnsonii CFII-96 and Acinetobacter guillouiae CFII-98 were characterized in detail and used further in our research. In the first phase, the strains were cultivated on Nutrient Agar medium and further grown in $100 \mathrm{~mL}$ Erlenmeyer flask with $30 \mathrm{~mL}$ Minimal Medium and 500 $\mathrm{mgL}^{-1}$ phenol as sole carbon and energy source. Five $500 \mathrm{~mL}$ batch bioreactors were used to treat synthetic wastewater in 48 hour interval with organic content of $1000 \mathrm{mgL}^{-1} \mathrm{COD}$ and additional $500 \mathrm{mgL}^{-1}$ of phenol. In the first three bioreactors the three microorganisms were inoculated separately with an initial of $0.5 \mathrm{OD}_{590}$ cell density with a volume of $25 \mathrm{~mL}$ inoculum to $475 \mathrm{~mL}$ wastewater. The fourth bioreactor was inoculated with the consortia prepared from the three isolated strains (equal mixture from each) having the same OD and volume as in the other bioreactors. The stability of phenol in the system was monitored by using a control bioreactor where beside wastewater and phenol no other microorganisms were introduced during the measurement.

Phenol removal rate of $98 \%$ was achieved in the $16^{\text {th }}$ hour in three bioreactors containing strains CFII- 87 , CFII-98 and consortia, while strain CFII-96 reached $98 \%$ phenol removal efficiency in $32^{\text {nd }}$ hour. Biomass concentration showed strong negative correlation with phenol, in each reactor there was substantial increase only in the presence of phenol suggesting that the microorganisms preferred phenol as carbon and energy source despite other organic matter found in the synthetic wastewater. During the analysis, autotrophic contamination was excluded because variation in the concentration of ammonia and nitrate in each reactor was insignificant. The difference between initial non-phenolic COD of $1000 \mathrm{mgL}^{-1}$ and the residual non-phenolic COD concentration of approx. $800 \mathrm{mgL}^{-1}$ in the case of CFII87, CFII98 and consortia did not change substantially during 48-hour batch analysis, only in the case of CFII96 the residual COD of approx. $525 \mathrm{mgL}^{-1} \mathrm{was}$ observed. The stability of the COD values indicate that beside phenol the majority of microorganisms did not adapt during the 48-hour batch test to the use of other carbon sources found in the wastewater. 
According to our measurements, the selected bacterial strains and consortia showed great affinity to phenol, utilizing it as carbon source, thus their use in bioaugmentation of wastewater bioreactors represents viable potential to increase the phenol removal rate of these systems.

\section{References}

[1] A. Nuhoglu and B. Yalcin, "Modelling of phenol removal in a batch reactor," Process Biochem, vol. 40, pp. 1233$1239,2005$.

[2] V. Arutchelvan, V. Kanakasabai, R. Elangovan, S. Nagarajan, V. Muralikrishnan, "Kinetics of high strength phenol degradation using Bacillus brevis," J. Hazard. Mater., vol. 29, pp. 216-222, 2006.

[3] A. M. Hannaford and C. Kurk, "Aerobic batch degradation of phenol using immobilized Pseudomonas putida," J. Ind. Microbiol Biotech, vol. 22, pp. 121-126, 1999.

[4] I. Nopensm, C. Capalozza, P. A. Vanroleghem (2001) [Online]. Available:

http://modeleau.fsg.ulaval.ca/fileadmin/modeleau/documents/Publications/pvr334.pdf 